\title{
O regime de metas de inflação foi a melhor escolha para o Brasil?
}

\author{
Ricardo Aguirre Leal* \\ Flavio Tosi Feijó ${ }^{* *}$
}

\begin{abstract}
RESUMO - O objetivo deste artigo é apresentar as opções de regimes monetários que defrontavam a autoridade monetária brasileira com o fim do câmbio fixo em janeiro de 1999 e verificar se a escolha pelo regime de metas de inflação foi a mais adequada. Através da análise dos aspectos teóricos, das vantagens e desvantagens de cada regime e, dado o histórico de instabilidade da inflação e falta de credibilidade da autoridade monetária brasileira concluiu-se que o regime de metas de inflação foi a melhor escolha para aquele momento.
\end{abstract}

Palavras-chave: Regimes monetários. Metas de inflação. Brasil.

\section{INRODUÇÃO}

A partir da década de 1990 o regime de metas de inflação passou a ser adotado em diversos países do mundo como alternativa para a condução da política monetária e manutenção da estabilidade dos preços. A Nova Zelândia foi o primeiro país a assumir formalmente este regime, no ano de 1990, seguida por Canadá e Chile em 1991, depois por Reino Unido, Israel, Suécia e outros.

Outros regimes monetários formais com âncoras nominais, cada qual com suas vantagens e desvantagens específicas, já haviam sido estudados e experimentados anteriormente. Como âncora cambial figurava o regime de metas cambiais (câmbio fixo); e como regimes de âncoras monetárias havia, além do regime de metas de inflação, o de metas de agregados monetários e o de metas de inflação implícita.

O Brasil adotou as metas de inflação em 1999, como estratégia político-monetária para conduzir as expectativas inflacionárias dos brasileiros após o abandono do já insustentável câmbio fixo. E, mesmo ao completar 12 anos de aplicação em junho deste ano (2011), ainda existe a discussão se a meta de inflação foi a melhor opção ao país naquele momento.

Neste artigo serão apresentados todos os regimes monetários citados anteriormente, no intuito de oferecer um panorama das práticas econômicas de política monetária, evidenciando os aspectos teóricos e as vantagens e desvantagens dos regimes. Esta exposição permitirá a

\footnotetext{
* Bacharel em ciências econômicas pela Universidade Federal do Rio Grande do Sul - FURG. Endereço eletrônico: raguirreleal@yahoo.com.br.

** Doutor em economia e professor adjunto da Universidade Federal do Rio Grande do Sul. Endereço eletrônico: tosift@yahoo.com.br.
} 
análise e a qualificação daquela medida econômica realizada pelo Brasil, a adoção do regime de metas de inflação, verificando se esta estratégia foi, ou não, a melhor escolha possível naquele momento.

\section{REGIMES MONETÁRIOS}

Como sabido, regimes monetários de âncoras nominais são estratégias político-monetárias que têm como meta o controle de preços, tanto por meio do controle das expectativas de inflação quanto pela indicação à formação dos preços do mercado. Essas práticas foram experimentadas (pelo menos as citadas neste trabalho), cada qual com suas peculiaridades, e em todas se percebe vantagens e desvantagens. Diante delas, aqui não é apontado a melhor ou a de maiores vantagens na forma abrangente, pois uma pode ultrapassar outra, inicialmente vantajosa, dependendo do cenário político-econômico presente. É sim estudada a melhor opção monetária, ponderando vantagens/desvantagens, diante do cenário específico em questão. Ademais, mesmo se fosse esgotada toda a teoria referente ao estudo,

Cabe recordar a velha lição: estamos tratando de policy, ou seja, Política Econômica. E policy é arte, não é teoria (embora a teoria dê fundamento à ação, obviamente). É, pois, um campo em que se fazem necessários engenho e arte. Não há receitas prontas, o mundo é complexo, a vida é perigosa, o Brasil é complicado (VELLOSO, 2005, p. XXXI).

\subsection{METAS DE TAXA DE CÂMBIO}

Este regime de âncora nominal ao câmbio, estabelecido em uma economia através de decisão do governo ou de uma lei, é geralmente adotado diante do registro de uma inflação muito elevada e que tenha causado grande descrédito da moeda doméstica junto aos mercados financeiros, impossibilitando a autoridade monetária de estabilizar os preços sem utilizar-se de um atrelamento a uma moeda forte de um país com estabilidade. O governo tenta mostrar aos mercados financeiros seu compromisso com o objetivo e passa a amarrar sua moeda à do país estrangeiro de acordo com a taxa de câmbio, conduzindo a política monetária de forma "automática" para obter expectativas estáveis.

Carvalho et al. (2007, p. 342) explicam a ação do governo neste regime, lembrando que:

Para evitar que as pressões de mercado - isto é, a disputa entre os compradores de moeda estrangeira escassa - façam a taxa de câmbio subir, o governo deve oferecer no mercado aquela quantidade de divisas que estaria faltando [...] para equilibrar oferta e demanda à paridade fixada. 
Logo em seguida os autores também advertem que "o Banco Central precisa dispor de reservas internacionais para intervir no mercado de câmbio e com isso garantir a manutenção da paridade fixa”. Pois, "a fixação da taxa de câmbio é responsabilidade das autoridades monetárias - e não do mercado".

Nunes e Meurer (2006, p. 84) colocam que a maior desvantagem destes sistemas advém do que Robert Mundell denominou de trindade impossivel: "a impossibilidade da economia manter, simultaneamente, taxa de câmbio fixa, mobilidade de capital e a politica monetária dedicada aos objetivos domésticos". Também explicam que a escolha deste regime, sob plena mobilidade de capitais, conduzirá "a taxa de juros doméstica a convergir para a do país âncora, não podendo utilizar a política monetária em resposta a choques domésticos diferentes do que ocorrem no país âncora".

Nesse tipo de regime a taxa de juros atua como a variável doméstica de ajuste externo. Dezordi (2004, p. 9) explica que "administrar a conta capital e o equilíbrio macroeconômico, em períodos de crises externas, significa elevar significativamente a taxa de juros doméstica, evitando a fuga de capitais e ataques especulativos que resultam em mudança de regime cambial".

A âncora cambial pode ocorrer em duas formas, a forma pura e a forma ajustável. A primeira engloba os sistemas cambiais de padrão-ouro e os chamados hard pegs: a dolarização e o currency board. Na segunda forma temos os soft pegs que incluem os sistemas de bandas de flutuação, zonas-alvo (ou moving target zone) e crawling peg (ou minidesvalorizações) (DEZORDI, 2004). A Figura 1 esquematiza o exposto acima:

FIGURA 1 - SISTEMAS MONETÁRIOS DE ÂNCORAS CAMBIAIS

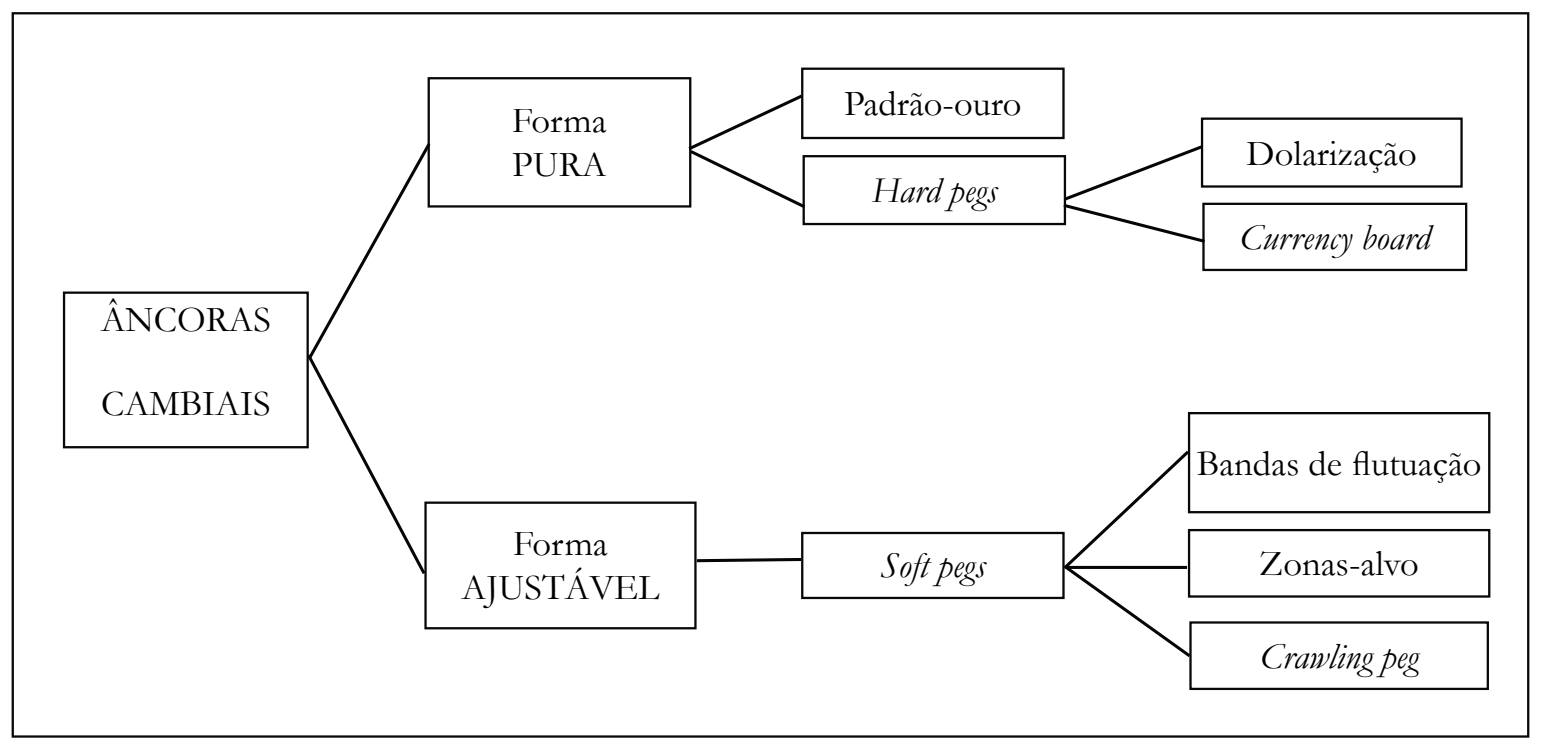

FONTE: Elaboração própria, com base no texto de Dezordi (2004). 
O Brasil adotou o sistema crawling peg a partir de 1968, utilizando-se de pequenas desvalorizações periódicas, executadas no intuito de seguir o ritmo da inflação pretérita (minidesvalorização passiva). Araújo e Silveira Filho (2002) expõem que, mesmo não sendo anunciada uma regra explícita de controle do câmbio, o Banco Central do Brasil guiava os ajustes, grosso modo, de acordo com a Paridade do Poder de Compra (PPC) relativa, monitorando a diferença entre a inflação do Brasil e a dos Estados Unidos (país âncora).

Em 1994, com a implantação do Plano Real, a política cambial passou por diversas fases, inclusive a de livre flutuação. Após 1995, entre novos experimentos de política cambial, houve uma gradual migração para as minidesvalorizações ativas (desvinculação da inflação pretérita). Em 1996, após a cristalização do sistema, o ritmo da desvalorização deixou de ser ligado à inflação passada (CARVALHO et al., 2007). A partir de 1997 a taxa de inflação passou a cair abaixo do ritmo da desvalorização do câmbio, criando desvalorizações reais da moeda de forma paulatina. Este regime cambial foi utilizado até o início de 1999 quando passou a ser adotado o câmbio flutuante.

Neste período após o Plano Real a dívida líquida como proporção do PIB aumentava aceleradamente $^{1}$ em função das taxas de juros extremamente altas $^{2}$, praticadas no intuito de atrair capitais estrangeiros e compensar o Balanço de Pagamentos pelos déficits crescentes na conta corrente, bem como manter os níveis das necessárias reservas internacionais. Ocorreu uma rápida deterioração do saldo do movimento de capitais junto ao aumento de demanda interna por moeda estrangeira devido à queda da credibilidade do sistema. Logo se iniciou uma incrível diminuição das reservas internacionais, pressionada pelo câmbio. Em janeiro de 1999 o $\mathrm{BCB}$ viu-se obrigado a flexibilizá-lo, pois, caso se mantivesse a sistemática, talvez logo fossem exauridas as reservas do país, que, ao final desse mês, experimentou queda de mais de $19 \%$ em 30 dias.

\subsection{METAS MONETÁRIAS}

No regime de metas monetárias, defendida por Milton Friedman, basicamente buscase a estabilidade de preços por meio de um ajustamento do crescimento da moeda nominal, por parte da autoridade monetária, que corresponda à taxa de inflação pretendida.

Até a década de 1990, em alguns países da OCDE (Organização para a Cooperação e Desenvolvimento Econômico), inclusive os Estados Unidos, a política monetária normalmente era conduzida conforme os regimes de metas de agregados monetários (ou metas de crescimento da 1 A dívida líquida do setor público em relação ao PIB foi de 31,4\% em 1996, 34,4\% em 1997, 42,4\% em 1998 e 46,9\% em 1999 (Banco Central do Brasil, 1999).

2 Isso se justifica por grande parte dos títulos referente à dívida pública interna terem sido atreladas à taxa SELIC. 
moeda) (BLANCHARD, 2007). Na verdade, esse regime era quase que um consenso internacional devido à contra-revolução monetarista, que ganhou diversos adeptos devido às crises dos anos 1970 e 1980. Grosso modo, o Banco Central anunciava um intervalo de variação no médio prazo para a taxa de crescimento da moeda nominal, permitindo-se alguns desvios no curto prazo de acordo com suas necessidades e intenções. Calculava seu crescimento de moeda basicamente somando a taxa de crescimento normal do produto (onde a taxa de desemprego é constante) com a inflação pretendida.

Certo número desses países da OCDE abandonou o regime de metas monetárias aderindo às metas de inflação. $O$ fato se deu principalmente após ter-se percebido a impossibilidade de se conduzir eficientemente as economias conciliando taxas de inflação pretendidas com deslocamentos imprevisíveis de demanda por moeda ${ }^{3}$ (BLANCHARD, 2007; CARVALHO et al., 2007). De acordo com Blanchard (2007), aqueles países experimentaram que a relação entre crescimento da moeda e inflação não é tão estreita quanto acreditavam. Curvas anuais de médias decenais (médio prazo) destas variáveis demonstraram que agregados monetários e inflação podem ter conduta adversa, pois o comportamento da demanda por moeda, que é variável e imprevisível, afeta sobremaneira o crescimento da moeda. Exemplo disso ocorreu na década de 1980, na qual os Estados Unidos experimentaram durante tempo considerável uma diminuição da inflação ao lado de um crescimento de M1 (moeda manual mais depósitos à vista).

Dezordi (2004, p. 13) lembra, conforme a estratégia monetarista, que "o regime de metas monetárias é compatível com um regime cambial flutuante, pois necessita de autonomia da política monetária doméstica". E, dessa forma, “oferece condições ao Banco Central em utilizar este instrumento de política econômica para estabilizar o produto nacional e evitar grandes desestabilizações".

Sem dúvida, esse regime é o que apresenta maior grau de transparência e entendimento das medidas adotadas na estratégia da política monetária, lhe propiciando benefício no combate à inflação. Porém, a desvantagem da ignorância nos desvios de demanda por moeda parece suplantar essa vantagem.

\subsection{METAS DE INFLAÇÃO IMPLÍCITA ${ }^{4}$}

Esta política é similar à de metas de inflação (explícita), que será estudada a seguir, porém faz uso da âncora sem o anúncio de metas.

No caso dos Estados Unidos, adepto ao regime e alvo do estudo de Mishkin (1999),

3 A demanda por moeda, na versão de Friedman, está relacionada (causalidade) à teoria da velocidade de circulação da moeda da TQM (Teoria Quantitativa da Moeda) e é entendida por ele como uma variável estável.

4 Este tópico é baseado em Mishkin (1999). 
embora não haja uma estratégia explícita de metas, há uma âncora nominal implícita que busca o controle da inflação por meio de uma coerente conduta da política monetária.

A falta de exposição das metas, ainda que seja adotada uma regra implicitamente, permite alto nível de discricionariedade. A autoridade monetária tem amplos poderes de adotar as medidas que julga procedente e, por isto, alguns autores denominam este regime de just do it. A discricionariedade é uma variável negativamente relacionada à credibilidade da política monetária. Por isso que as constantes tentativas dos agentes de captar as intenções do Banco Central, motivadas pela falta de transparência, geram “[...] desnecessária volatilidade em mercados financeiros e desperta incerteza entre os produtores e o público em geral sobre o curso futuro da inflação e produção também" (MISHKIN, 1999, p. 28).

O principal argumento na defesa da utilização do just do it é o sucesso que vem sendo alcançado pelos Estados Unidos na manutenção da estabilidade monetária com a utilização dessa estratégia. Já a principal desvantagem levantada pelo autor são as causas da falta de transparência da política monetária. Isto deixa os formuladores da política monetária mais suscetíveis ao problema da inconsistência dinâmica (viés inflacionário), visto que permitem-se alcançar objetivos de curto prazo às expensas dos de longo prazo. Outro problema sério é a dependência do sucesso econômico à personalidade e capacidade do(s) responsável(eis) pela condução da política monetária, normalmente o presidente do Banco Central. Por isso Mishkin defende a adoção do regime de metas de inflação, pelo menos no caso dos Estados Unidos.

\subsection{METAS DE INFLAÇÃO}

$\mathrm{O}$ regime de metas de inflação (inflation targeting) é a política monetária que utiliza como âncora nominal a própria inflação para atingir a estabilidade de preços $^{5}$, estabelecendo explicitamente uma meta de inflação, pontual ou intervalar, no médio prazo.

Ele tem seu alicerce teórico basicamente junto ao arcabouço da síntese neoclássica, que incorporou a relação proposta anteriormente por Willian Phillips (curva de Phillips), e à corrente monetarista de Milton Friedman, que defendia a ideia de uma taxa natural de desemprego e afirmava que políticas monetárias afetam claramente as variáveis reais da economia, porém não de forma duradoura (curva de Phillips aceleracionista). Contudo, foram as proposições novo-clássicas com as expectativas racionais de forward-looking que pregavam esse tipo de política monetária aliada à criação de bancos centrais independentes para, juntos, reduzirem os estímulos à implementação de políticas de surpresa monetária, devidas principalmente ao viés inflacionário e à discricionariedade dos

5 O regime de metas de inflação difere-se do regime de metas de inflação implícita pelo anúncio das metas que pretende atingir, o que não ocorre neste segundo. 
administradores da política econômica.

A alternativa do regime de metas de inflação possibilita a utilização do câmbio flutuante e traz os benefícios decorrentes da possibilidade de ajustes na taxa de juros. Permite um controle estreito e visível da âncora e é prontamente compreendido pelos agentes, altamente transparente e permite a discricionariedade na administração da política monetária - também permite uma regra no lugar desta - outrossim, porque aumenta a responsabilidade do Banco Central e constrange impulsos expansionistas, diminuindo o problema da inconsistência dinâmica.

\section{ESCOLHA DO REGIME}

Como explicado anteriormente, com a flexibilização do câmbio o Brasil viu-se sem uma âncora nominal na condução da política econômica de estabilidade de preços. Segundo Modenesi (2005), era imprescindível a utilização de uma nova âncora econômica condutora das expectativas dos agentes, que norteasse a formação dos preços na direção indicada pela autoridade monetária, pois "em um sistema econômico historicamente caracterizado por um elevado grau de instabilidade, como a economia brasileira, as expectativas dos agentes econômicos com relação à inflação [...] [são] muito elásticas” (MODENESI, 2005, p. 359). E o país enfrentou esse dilema, que ao fim culminou com a escolha pelas metas de inflação em julho de 1999. Contudo, cabe verificar se esta decisão foi acertada ou não.

Sobre a âncora cambial, observa-se mediante o estudo das suas diversas formas que nenhuma delas, caso adotadas (ou mantidas), atingiriam o objetivo econômico proposto, visto a desvantagem imposta pela trindade impossível. Ou seja, estes sistemas não controlariam as expectativas inflacionárias dos agentes naquele momento, pois eles não acreditariam nos anúncios de estabilidade manifestados pela autoridade monetária. O câmbio fixo, tanto na forma pura quanto na forma ajustável, não possuía mais espaço como âncora para o Brasil naquele momento, também devido às já mirradas reservas internacionais. Assim, fica justificado para este trabalho, ainda que sumariamente, a não continuidade das âncoras cambiais em qualquer das formas apresentadas, no entanto, sem condenar o uso destas no momento oportuno.

Em relação às metas monetárias, é fácil entendermos a recusa desta opção. No discurso de anúncio do novo regime, Pedro Malan (então Ministro da Fazenda) explica o descarte:

Nós não somos monetaristas, não acreditamos na estabilidade dessa relação [entre algum agregado monetário relevante e o comportamento da inflação a médio e longo prazo], não acreditamos na estabilidade da velocidade de renda/circulação da moeda. Não acreditamos portanto que essa seja uma base para estruturação da forma de condução da política monetária do Brasil. 
Portanto, nós o eliminamos [regime de metas monetárias] (MALAN, 1999).

A explicação é análoga ao estudado a pouco, onde se viu, entre outras, que os Estados Unidos e outros países da OCDE desistiram do sistema de metas monetárias após a evidência empírica, além da teórica, de que há defasagens na relação entre agregados monetários e inflação. As vantagens do regime, apesar de grandes, se mostraram menores que a desvantagem da imprevisibilidade dos desvios de demanda por moeda e a consequente ignorância sobre o quantum de moeda a ser ofertada. O sistema não controlaria as expectativas inflacionárias dos agentes. Também fica explicada sumariamente a rejeição do regime de metas monetárias pelo Brasil.

Por fim, sobre as metas de inflação implícita e seu alto nível de discricionariedade, vale lembrar a necessidade da credibilidade econômica e da reputação da autoridade monetária na condução eficaz desse regime. Sobre isso, Pedro Malan (1999) comentou que:

\footnotetext{
Em alguns casos uma credibilidade foi angariada ao longo de décadas na busca desse objetivo [estabilidade de preços]. O caso mais conhecido no mundo é o do Federal Reserve $[\mathrm{BC}]$ dos Estados Unidos, que não tem nenhuma meta explícita nem para agregado monetário, nem para câmbio e nem para inflação, e que, não obstante, tem um comportamento que lhe rendeu uma grande credibilidade junto ao mercado pela sua determinação de, apesar de não ter metas, ter uma postura de controle da inflação sempre olhando a médio e longo prazo, que é hoje reconhecida internacionalmente.
}

Os agentes daquele país acreditam na política da autoridade monetária, pois, como disse Malan (1999), há uma credibilidade presente conquistada ao longo de décadas, com políticas econômicas bem-sucedidas. Também não é necessário grande esforço para perceber a incapacidade de o Brasil assumir de forma eficaz esse sistema naquele momento. Como é de conhecimento geral, o país amargurava desde a década de 1980 um insistente processo de aceleração inflacionária concomitante com alguns anos de recessões. A inércia inflacionária e a indexação da economia não facilitavam em nada na credibilidade dos agentes. E o então Ministro da Fazenda reconheceu implicitamente a falta de credibilidade da economia brasileira e a impossibilidade de assunção desse regime, assim como, sabidamente, descartou a opção.

Conclui-se, então, que a decisão do governo entre as âncoras nominais, foi a melhor resposta possível às estratégias dos demais agentes, que tinham, por sua vez, como melhor opção, não acreditar nas promessas de estabilidade. Parece então, após a análise realizada, que a decisão pelo regime de metas de inflação foi correta; que foi a melhor dentre as possíveis escolhas que se poderia fazer naquele momento. 
Contudo, nos dias atuais, a melhor escolha pelo sistema monetário pode ser diferente, visto que ocorreram mudanças na conjuntura econômica do país: principalmente nas variáveis credibilidade e reputação, que sofreram incrementos consideráveis desde a década de 1990. Neste contexto se faz necessário, para analisar um novo processo decisório, outro estudo mais específico e elaborado, não realizado por este trabalho.

\section{REFERÊNCIAS}

ARAÚJO, C. H. V.; FILHO, G. B. da. S. Mudanças de regime no câmbio brasileiro. Brasília, n. 41, p. 1-41, Jun. 2002. Discussão.

BANCO CENTRAL DO BRASIL. Boletim do Banco Central do Brasil. Relatório 1999. Brasília, v. 35, p. 1-250, 1999.

BLANCHARD, O. Macroeconomia. São Paulo: Pearson Prentice Hall, 2007.

CARVALHO, F. J. C. de.; SOUZA, F. E. P. de.; SICSÚ, J.; PAULA, L. F. R. de.; STUDART, R. Economia Monetária e Financeira. Rio de Janeiro: Elsevier, 2007.

DEZORDI, L. L. A condução da política monetária brasileira no regime de metas de inflação uma abordagem teórica. $134 \mathrm{f}$. Dissertação (Mestrado) - Curso de Mestrado em Desenvolvimento Econômico, Universidade Federal do Paraná, Curitiba, 2004.

MALAN, P. Transcrição do pronunciamento do ministro Pedro Malan ao anunciar as metas inflacionárias para o triênio 1999-2001. Pronunciamentos. Ministério da Fazenda. Brasília, 1999. Não paginado.

MISHKIN, F. S. International experiences with different monetary policy regimes. NBER Working Paper Series, Cambridge, n. 6965, 46 p., Fev. 1999.

MODENESI, A. M. Regimes monetários: teoria e a experiência do real. 1. ed. Barueri: Manole, 2005.

NUNES, M. S.; MEURER, R. Arranjos cambiais, crises monetárias e o papel das instituições na escolha de taxas de câmbio: um estudo para economias emergentes. Teoria e Evidência Econômica, Passo Fundo, v. 14, n. 27, p. 82-100, nov. 2006.

VELLOSO, J. P. R. Regime Monetário e Estabilização como Parte da Política de Desenvolvimento. In: MODENESI, A. M. Regimes monetários: teoria e a experiência do real. 1. ed. Barueri: Manole, 2005. Apresentação, p. XXXI-XXXIII. 
